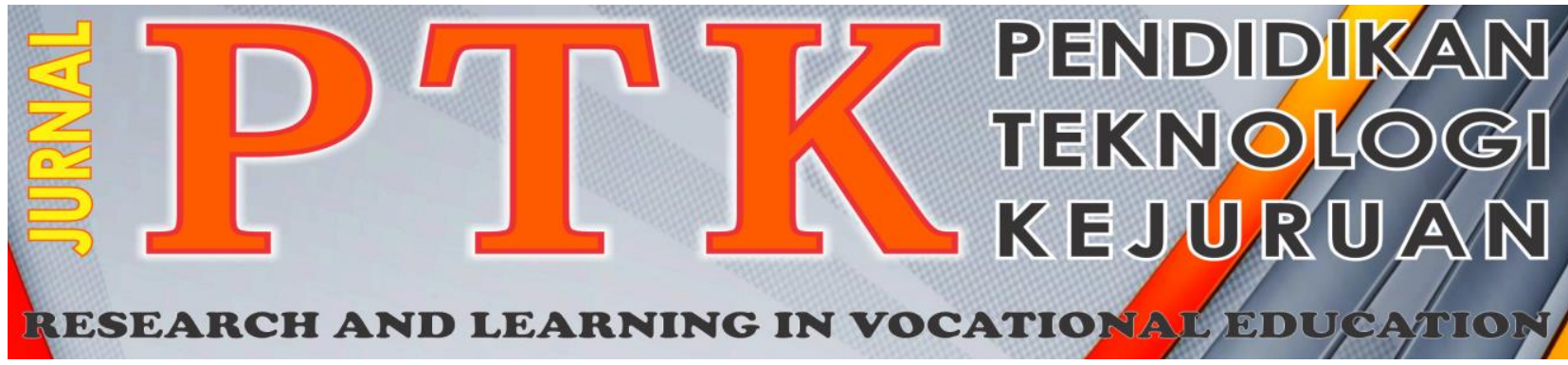

Vol. 1, No. 4, 2018

P-ISSN: 2621-3273

E-ISSN: 2621-1548

\title{
Hubungan Gaya Belajar dengan Hasil Belajar Mahasiswa PKK Tata Busana Fakultas Pariwisata dan Perhotelan Universitas Negeri Padang
}

\author{
Ridha Yulian ${ }^{1}$, Ernawati ${ }^{2}$, \\ ${ }^{1}$ Prodi Pendidikan Kesejahteraan Keluarga, Fakultas Pariwisata dan Perhotelan, Universitas Negeri Padang \\ ${ }^{2}$ Fakultas Pariwisata dan Perhotelan, Universitas Negeri Padang \\ *Corresponding author, Email : ridhayulian94@gmail.com
}

\begin{abstract}
Abstrak - Tujuan penelitian untuk mendeskripsikan gaya belajar dan hubungannya dengan hasil belajar mahasiswa prodi PKK Tata Busana UNP. Metode penelitian menggunakan pendekatan kuantitatif korelasional. Teknik pengambilan sampel dengan Proporsional Random Sampling. Besar sample adalah 73 mahasiswa dengan menggunakan rumus Slovin. Instrument penelitian yang digunakan berupa kuisioner. Hasil penelitian menunjukkan bahwa gaya belajar yang dominan pada mahasiswa adalah gaya belajar auditorial. Hasil belajar mahasiswa pada umumnya berada dalam predikat sangat memuaskan. Hasil uji Regresi menunjukkan gaya belajar tidak memiliki hubungan yang signifikan dengan hasil belajar mahasiswa, dimana nilai Sig yang diperoleh lebih besar dari 0.05 yaitu $0.220>0.05$. Gaya belajar memiliki keeratan hubungan 4.3\% dengan hasil belajar mahasiswa.
\end{abstract}

Kata kunci：Gaya belajar, Visual, Auditori, Kinestetik, Hasil belajar

Abstract- The purpose of the study was to describe the learning style and that relationship with the learning outcomes of the students of the UNP PKK Tata Busana. The research method uses correlational quantitative approach. Sampling technique with proportional random sampling. The sample is 73 students using the Slovin formula. The research instrument used was a questionnaire. The results showed that the dominant learning style in students was an auditory learning style. Student learning outcomes generally are in a very satisfying predicate. Regression test results show that learning styles do not have a significant relationship with student learning outcomes, where the Sig values obtained are greater than 0.05 , which are $0.220>0.05$. Learning styles have a close relationship of $4.3 \%$ with student learning outcomes.

Keywords: Learning style, Visual, Auditory, Kinesthetic, Learning outcomes

\section{Pendahuluan}

Prodi Pendidikan Kesejahteraan Keluarga Tata Busana Fakultas Pariwisata dan Perhotelan Universitas Negeri Padang merupakan program studi yang dalam kegiatan pembelajarannya meliputi teori dan praktek. Mahasiswa yang mengambil Prodi PKK diharapkan mampu mengikuti pembelajaran sesuai dengan tujuan prodi. Pembelajaran yang diberikan bertujuan mempersiapkan mahasiswa yang tidak hanya berorientasi pada pengetahuan semata tetapi juga dipersiapkan pada bidang keterampilan.

Saat kita membahas tentang pendidikan berarti kita membahas tentang proses belajar. Keberhasilan suatu proses pendidikan pada setiap jenjang pendidikan bergantung pada proses belajar yang dialami oleh peserta didiknya [1]. Belajar adalah suatu aktivitas mental/psikis, yang berlangsung dalam interaksi aktif dengan lingkungan yang menghasilkan perubahan dalam pengetahuan, keterampilan dan sikap [2]. Setiap pelajar pada hakikatnya memiliki perbedaan satu dengan yang lainnya, perbedaan tersebut akan berakibat pada kegiatan belajar, seperti soal kreativitas dan gaya belajar bahkan juga dapat membawa akibat perbedaan dalam hal hasil belajar siswa [3]. Salah satu faktor yang bisa menunjang dalam pembelajaran adalah gaya belajar, terutama gaya belajar yang mendukung pembelajaran yang diikuti. 
Kunci menuju keberhasilan dalam belajar dan bekerja adalah mengetahui gaya belajar atau bekerja yang unik dari setiap orang, menerima kekuatan sekaligus kelemahan diri sendiri dan sebanyak mungkin menyesuaikan preferensi pribadi dalam setiap situasi pembelajaran, pengkajian maupun pekerjaan [4].

Banyak orang tidak menyadari bahwa mereka lebih suka dan memiliki sebuah gaya belajar karena tidak ada sesuatu eksternal yang mengatakan kepada mereka bahwa mereka berbeda dengan orang lain [5]. Ketika seseorang tahu gaya belajarnya kemudian dia menerapkannya dalam proses belajar, dia akan bisa belajar lebih mudah dan cepat [6]. Jadi, pemahaman tentang gaya belajar merupakan salah satu hal yang bisa dipertimbangkan pada proses dan hasil pembelajaran.

Tujuan dari penelitian ini adalah mendeskripsikan gaya belajar dan hubungannya dengan hasil belajar mahasiswa prodi Pendidikan Kesejahteraan Keluarga Keahlian Pendidikan Tata Busana Jurusan Ilmu Kesejahteraan Keluarga Fakultas Pariwisata dan Perhotelan Universitas Negeri Padang.

\section{STUdi PUSTaKa}

Hasil belajar merupakan kemampuan yang diperoleh individu setelah proses belajar berlangsung, yang dapat memberikan perubahan tingkah laku baik pengetahuan, pemahaman, sikap dan keterampilan siswa sehingga menjadi lebih baik dari sebelumnya [7]. Seseorang dianggap telah belajar jika ia dapat menunjukkan perubahan tingkah laku dan pengetahuannya [8]. Merson U. Sangalang mengemukakan 6 faktor yang mempengaruhi hasil belajar yaitu intelegensi, minat dan bakat, faktor motif, gaya belajar, lingkungan keluarga dan lingkungan rumah [9].

Gaya belajar seseorang adalah kombinasi dari diri seseorang bagaimana ia menyerap dan kemudian mengatur serta mengolah informasi [5]. Ada beberapa pendekatan untuk mengkategorikan gaya belajar, dari berbagai pendekatan tersebut yang paling sering digunakan di Indonesia adalah pendekatan modalitas sensori atau panca indera [10]. Jenis gaya belajar menurut sensori yaitu gaya belajar visual, gaya belajar auditori dan gaya belajar kinestetik [5].

Adapun ciri-ciri karakteristik dari setiap gaya belajar menurut DePorter \& Hernacki, adalah sebagai berikut [5] :

1. Gaya Belajar Visual

Gaya belajar visual menitikberatkan penyerapan informasi/materi pelajaran pada indera penglihatan yang ditandai dengan ciri sebagai berikut : a).Rapi dan teratur; b.Berbicara dengan cepat; c).Perencana dan pengatur jangka panjang yang baik; d).Teliti secara mendetail; e).Mementingkan penampilan baik dalam hal pakaian ataupun presentasi; f).Pengeja yang baik dan dapat melihat kata-kata yang sebenarnya dalam pikiran mereka; g).Mengingat apa yang dilihat, daripada yang didengar; h).Mengingat dengan asosiasi visual; i).Biasanya tidak terganggu dengan keributan; j).Pembaca yang cepat dan tekun; k).Lebih suka membaca daripada dibacakan, 1).Membutuhkan pandangan dan tujuan yang menyeluruh dan bersikap waspada sebelum secara mental merasa pasti tentang suatu masalah atau proyek; m).Mencoret tanpa arti selama berbicara di telepon atau dalam rapat; n).Sering menjawab pertanyaan dengan jawaban yang singkat ya atau tidak; o).Lebih suka melakukan demonstrasi daripada berpidato

2. Gaya Belajar Auditorial

Gaya belajar auditorial menitikberatkan penyerapan informasi/materi pelajaran pada indera pendengaran yang ditandai dengan ciri sebagai berikut : a).Lebih suka musik daripada seni lukis b).Berbicara dengan diri sendiri saat bekerja: c).Mudah terganggu dengan keributan d).Menggerakkan bibir mereka dan mengucapkan tulisan di buku saat membaca; e).Senang membaca dengan keras dan mendengarkan: f).Hebat dalam bercerita dan memulai percapakapan: g)Berbicara dalam irama yang terpola: h).Belajar dengan mendengarkan dan mengingat apa yang didiskusikan daripada apa yang telah dilihat. i).Suka berbicara dan bergurau bahkan di dalam kelas; suka diskusi dan menjelaskan sesuatu secara panjang lebar; j).Lebih suka gurauan lisan daripada tulisan.

3. Gaya Belajar Kinestetik

Gaya belajar kinestetik menitikberatkan penyerapan informasi/materi pelajaran pada indera indera perasa dan gerakan-gerakan fisik yang ditandai dengan ciri sebagai berikut : a).Berbicara dengan perlahan; b).Suka menyentuh segala sesuatu yang menarik yang dijumpainya; c).Menyentuh orang untuk mendapatkan perhatian; d).Berdiri secara dekat saat berbicara dengan orang lain; e).Selalu berorientasi pada fisik dan banyak bergerak; f).Mengingat secara baik bila secara fisik terlibat aktif dalam proses pembelajaran serta cepat belajar melalui praktik g).Menghafal dengan cara berjalan dan bergerak; h).Menggunakan jari sebagai penunjuk saat membaca buku; i).Banyak menggunakan isyarat tubuh: j).Tidak bisa duduk diam untuk waktu yang lama. 


\section{III.METODE}

Penelitian ini merupakan penelitian korelasional, yaitu penelitian yang dilakukan untuk melihat hubungan antara variabel-variabel yang terkait dalam penelitian tersebut [11]. Penelitian ini dilakukan untuk melihat hubungan antara gaya belajar dengan hasil belajar mahasiswa prodi PKK Tata Busana dilihat dari Indeks Prestasi Kumulatif (IPK). Penelitian dilakukan pada bulan Agustus 2018. Populasi penelitian adalah seluruh mahasiswa prodi PKK Tata Busana yang berjumlah 268 orang. Teknik pengambilan sample menggunakan Proportional Random Sampling. Sampel dalam penelitian ini adalah 73 orang mahasiswa yang ditentukan dengan menggunakan rumus Slovin.

Data penelitian ini adalah data primer dan data sekunder. Data primer diperoleh dari angket berupa kuesioner tentang gaya belajar mahasiswa prodi PKK Tata Busana. Kuesioner disusun berdasarkan indikator ciri gaya belajar visual, auditori dan kinestetik menurut pendapat DePotter (2001). Data sekunder adalah hasil belajar mahasiswa dilihat dari Indeks Prestasi Komulatif (IPK) yang diperoleh dari Data Administrasi Jurusan Ilmu Kesejahteraan Keluarga Universitas Negeri Padang.

Data dianalisis dengan uji univariat dan bivariat. Uji univariat dilakukan untuk menganalisis variabel bebas yaitu jenis gaya belajar dan variabel terikat yaitu hasil belajar mahasiswa prodi PKK Tata Busana. Hasil analisis dibuat dalam bentuk pesentase [12] :

$$
p=\frac{f}{n} \times 100 \%
$$

$p:$ Presentase

$f$ : Jumlah responden dari setiap variabel

$n:$ Jumlah responden keseluruhan

Uji bivariat dilakukan untuk menganalisis hubungan antara gaya belajar dengan hasil belajar mahasiswa. Untuk melihat hubungan gaya belajar dengan hasil belajar dilakukan uji Regresi dengan Probabilitas Sig yaitu 0.05. Sebelum uji Regresi, dilakukan uji prasyarat analisis yaitu uji normalitas dan linieritas untuk untuk memastikan bahwa data berdistribusi normal dan bersifat linear antar variabel.

\section{IV.HASIL DAN PEMBAHASAN}

Hasil dari penelitian yang dilakukan guna melihat gaya belajar mahasiswa prodi PKK Tata Busana menunjukkan bahwa dari 73 mahasiswa, $35.61 \%$ (26 orang) memiliki kecenderungan gaya belajar visual, $41.09 \% \quad(30$ orang $)$ memiliki kecenderungan gaya belajar auditorial dan $23.30 \%$ (17 orang) memiliki kecenderungan gaya belajar kinestetik. Hasil penelitian ini juga menunjukkan bahwa gaya belajar yang dominan pada mahasiswa Jurusan PKK Busana adalah gaya belajar auditorial.

Sementara itu untuk hasil belajar mahasiswa menunjukkan bahwa dari 73 mahasiswa yang menjadi responden, $41.1 \%$ (30 orang) memiliki prediket IPK dengan pujian, 57.53\% (41 orang) memiliki prediket IPK sangat memuaskan dan $1.37 \%$ (1 orang) memiliki prediket IPK memuaskan. Hasil penelitian ini juga menunjukkan bahwa hasil belajar mahasiswa PKK Tata Busana pada umumnya berada dalam predikat sangat memuaskan

Hasil penelitian hubungan gaya belajar dengan hasil belajar menunjukkan hasil yang tidak signifikan. Berdasarkan penelitian yang telah dilakukan, diperoleh nilai Sig sebesar 0.220. Jika dibandingkan nilai Sig besar dari Probabilitas Sig yaitu 0.05 , maka nilai $0.220>0.05$ sehingga dapat diartikan bahwa Ha ditolak. Berdasarkan hasil tersebut, dapat diinterpretasikan bahwa tidak terdapat hubungan yang signifikan antara gaya belajar dan hasil belajar mahasiswa prodi PKK Tata Busana.

Selanjutnya, nilai $\mathrm{R}$ Square $\left(\mathrm{R}^{2}\right)$ yang merupakan koefisinsi determinasi menunjukan nilai $0.043=4.3 \%$. Nilai ini menunjukkan bahwa gaya belajar memiliki hubungan sebesar $4.3 \%$ dengan hasil belajar mahasiswa. Sedangkan 95,7 \% dapat berasal dari variabel lain yang memiliki hubungan dengan hasil belajar mahasiswa. Berdasarkan hasil penelitian di atas dapat disimpulkan bahwa tidak ada hubungan yang signifikan antara gaya belajar dengan hasil belajar mahasiswa Prodi PKK Tata Busana.

Merson U. Sangalang mengemukakan bahwa selain gaya belajar faktor yang bisa mempengaruhi hasil belajar antara lain, intelegensi, faktor motif, minat dan bakat, lingkungan keluarga dan lingkungan pendidikan [9].

Intelegensi atau tingkat kecerdasan merupakan wadah bagi kemungkinan tercapainya hasil belajar yang diharapkan, sedangkan motif adalah dorongan dasar yang menggerakkan seseorang untuk melakukan sesuatu [13]. Faktor kecerdasan memiliki hubungan dengan hasil belajar mahasiswa [14].

Minat berarti kecenderungan dan kegairahan yang tinggi atau keinginan yang besar terhadap sesuatu, sedangkan bakat merupakan potensi yang dimiliki seseorang untuk mencapai keberhasilan pada masa yang akan datang [15] Minat dan bakat dapat mempengaruhi kualitas pencapaian hasil belajar. Mahasiswa yang menaruh minat besar terhadap bidang studi tertentu akan lebih memusatkan perhatiannya. sehingga memungkinkan siswa tersebut untuk belajar lebih giat dan pada akhirnya mencapai prestasi yang diinginkan. 
Keluarga merupakan salah satu media pendidikan yang amat penting dalam menentukan pembentukan kepribadian seseorang, karena dalam keluarga awalnya pendidikan dan pengajaran diberikan, disertai motivasi dan dorongan dari kedua orang tua [16]. Pendidikan orang tua, lingkungan keluarga serta faktor motivasi belajar memiliki hubungan dengan hasil belajar mahasiswa [17]

Lembaga pendidikan memiliki peranan dalam membentuk kepribadian dan mencerdaskan. Lingkungan pendidikan mempengaruhi pembelajaran dan pengajaran, seperti; metode mengajar, kurikulum, relasi pengajar dengan pelajar serta pelajar dengan pelajar, disiplin, waktu, keadaan fasilitas pendidikan, metode belajar dan materi [18]. Cara belajar memiliki hubungan dengan hasil belajar [19]. Keterampilan belajar memiliki hubungan dengan hasil belajar [20]. Motivasi berprestasi dan partisipasi mahasiswa dalam proses pembelajaran memiliki hubungan dengan hasil belajar mahasiswa [21]. Motivasi belajar dan lingkungan kemahasiswaan memiliki hubungan dengan hasil belajar mahasiswa. [22]

Gaya belajar mahasiswa prodi Pendidikan Kesejahteraan Keluarga Keahlian Pendidikan Tata Busana Fakultas Pariwisata dan Perhotelan Universitas Negeri Padang, dapat disimpulkan tidak memiliki hubungan yang signifikan dengan hasil belajar mahasiswa. Walau demikian faktor yang memiliki hubungan dengan hasil belajar bukan hanya berasal dari gaya belajar. Faktor lain seperti intelegensi, faktor motif, minat dan bakat, lingkungan keluarga dan lingkungan pendidikan juga memiliki andil dan hubungan dalam hasil belajar. Jika gaya belajar merupakan cara termudah seseorang untuk bisa belajar, maka intelegensi dan bakat merupakan modal atau potensi yang sudah dimiliki oleh dirinya. Faktor minat akan membantu keinginan dan ketertarikan dalam belajar, sedang faktor keluarga dan pendidikan menjadi pendukung untuk bisa mecapai hasil belajar yang diharapkan.

\section{KESIMPULAN}

Penelitian ini memberi informasi bahwa gaya belajar yang dominan dimiliki oleh mahasiswa Prodi PKK UNP adalah gaya belajar auditorial. Hasil belajar mahasiswa pada umumnya berada dalam predikat sangat memuaskan. Gaya belajar tidak memiliki hubungan yang signifikan dengan hasil belajar mahasiswa, walau demikian faktor lain bisa memiliki hubungan dan memeberi pengaruh pada hasil belajar mahasiswa Pembelajaran yang diberikan sebaiknya mendukung gaya belajar yang dimiliki mahasiswa. Selain hal tersebut bagi Prodi PKK UNP sebaiknya memilih mahasiswa yang memiliki gaya belajar yang sesuai dengan pembelajaran yang diberikan sehingga dapat membantu peningkatan hasil belajar.

\section{DAfTAR PUSTAKa}

[1] Djamarah, Syaiful. Strategi Belajar Mengajar. Jakarta: Rineka Cipta, 2006.

[2] W.S. Winkel. Psikologi Pengajaran. Jakarta: Grasindo, 2004.

[3] Sardiman. Interaksi dan Motivasi Belajar Mengajar. Jakarta: Raja Grafindo Persada, 2012.

[4] Papilaya, Jeanete Ophilia \& Neleke Huliselan,. "Identifikasi Gaya Belajar Mahasiswa" Jurnal Psikologi Universitas Diponegoro. Vol.15, No.1, pp. 56-63, 2016.

[5] Deporter \& Hernacki. Quantum Learning:Membiasakan Belajar Nyaman. Bandung: PT Mizan, 2001.

[6] Gilakjani. "Visual, Auditory, Kinestetik Learning Style and Their Impact on English Language Teaching" Jurnal of Studies in Education, Vol.2 , No.1, pp. 104-113, 2012.

[7] Purwanto, Ngalim. Psikologi Pendidikan. Bandung: Remaja Rosda Karya, 2002.

[8] Budiningsih, Asri. Belajar dan Pembelajaran. Jakarta: Rinekacipta, 2005.

[9] Tulus, Tu'u. Peran Disiplin pada Perilaku dan Prestasi Belajar. Jakarta:Grasindo, 2004.

[10] Gunawan, Adi. Genius Learning Style. Jakarta: Gramedia Pustaka Utama, 2004.

[11] Darmadi, Hamid. Metode Penelitian Pendidikan dan Sosial:Teori Konsep Dasar dan Implementasi. Bandung: Alfabeta, 2014.

[12] Sugiyono. Metode Penelitian Pendidikan:Pendekatan Kuantitatif, Kualitatif dan $R \& D$. Bandung: Alfabeta., 2017.

[13] Uno, Hamzah. Teori Motivasi dan Pengukurannya. Jakarta: Bumi Aksara, 2012.

[14] Rino. "Analisis Faktor-Faktor yang Mempengaruhi Hasil Belajar Mahasiswa Fakultas Ekonomi Universitas Negeri Padang". Jurnal Universitas Negeri Padang, 2008.

[15] Danim, Sudarwan. Perkembangan Peserta Didik. Bandung: Alfabeta, 2010.

[16] Slameto. Belajar dan Faktor-Faktor Yang Mempengaruhinya. Jakarta: Rineka Cipta, 2010.

[17] Hari, Rizki. "Hubungan Pendidikan Orang Tua, Lingkungan Keluarga dan Motivasi belajar terhadap Hasil Belajar Mahasiswa prodi Pendidikan Ekonomi Universitas Negeri Padang, 2013.

[18] Syah, Muhibbin. Psikologi Belajar. Jakarta: Raja Grafindo Persada, 2007.

[19] Rohati, Rida. "Hubungan Cara Belajar Terhadap Hasil Belajar Mahasiswa Prodi Pendidikan Kesejahteraan Keluarga konsentrasi Tata Boga Jurusan Ilmu Kesejahteraan Keluarga Fakultas Pariwisata dan Perhotelan Universitas Negeri Padang" Jurnal. Universitas Negeri Padang, 2014. 
[20] Zahri \& A.Muri Yusuf. "Hubungan Gaya belajar dan Keterampilan Belajar Terhadap Hasil Belajar Mahasiswa" Jurnal Psikologi Universitas Negeri Padang, 2016.

[21] Kurnia, Oldhy. "Pengaruh Motivasi Berprestasi dan Partisipasi Mahasiswa dalam Proses Pembelajaran Terhadap Hasil Belajar Mahasiswa Pendidikan Ekonomi Fakultas Ekonomi Universitas Negeri Padang”. Jurnal Universitas Negeri Padang., 2012.

[22] Oktarina, Cahyani. "Faktor yang Mempengaruhi Prestasi Akademik Mahasiswa Jurusan Matematika FMIPA Universitas Negeri Padang Menggunakan Analisis Regresi Logistik Biner". Jurnal Universitas Negeri Padang, 2010.

\section{Biodata Penulis}

Ridha Yulian, lahir di Padang, 15 Juli 1994. Mahasiswa Prodi Pendidikan Kesejahteraan Keluarga Tata Busana Fakultas Pariwisata dan Perhotelan Universitas Negeri Padang.

Ernawati, Dosen Fakultas Pariwisata dan Perhotelan Universitas Negeri Padang 